\title{
Base Deficit
}

National Cancer Institute

\section{Source}

National Cancer Institute. Base Deficit. NCI Thesaurus. Code C147309.

The determination of the amount of alkali required to return a biological specimen to a normal pH under standard conditions. 